\title{
rel \\ Bone density parathyroid hormone and 25-hydroxyvitamin D concentrations in middle aged women //
}

\author{
Kay-Tee Khaw, Mary-Jane, Sneyd, Juliet Compston
}

\begin{abstract}
Objective-To examine the relation between bone density and indices of calcium metabolism including parathyroid hormone and 25-hydroxyvitamin D concentrations in middle aged women.

Design - A cross sectional study.

Setting and subjects -138 women volunteers aged 45-65 with no known osteoporosis and unselected for disease status recruited for a dietary assessment study from the community using general practice registers. Volunteer rate was $20 \%$.

Main outcome measure-Bone mineral density measured with dual energy $x$ ray absorptiometry.

Results-Bone density at the lumbar spine and neck and trochanteric regions of the femur was inversely related to serum intact parathyroid hormone concentrations and positively related to serum 25-hydroxyvitamin D concentrations. These associations were independent of possible confounding factors, including age, body mass index, cigarette smoking habit, menopausal status, and use of diuretics and postmenopausal hormone replacement therapy. These associations were apparent throughout the whole distribution of bone density and 25-hydroxyvitamin $\mathbf{D}$ and parathyroid hormone concentrations within the normal range, suggesting a
\end{abstract} physiological relation.

Conclusions-The findings are consistent with the hypothesis that parathyroid hormone and 25-hydroxyvitamin D concentrations influence bone density in middle aged women. Findings from this study together with other work suggest that the role of vitamin $D$ in osteoporosis should not be neglected. The associations with parathyroid hormone also indicate plausible biological mechanisms. The roughly $5-10 \%$ difference in bone density between top and bottom tertiles of serum 25-hydroxyvitamin D concentrations, though not large in magnitude, may have considerable public health implications in terms of prevention of osteoporosis and its sequelae, fractures.

University of Cambridge School of Clinical Medicine Addenbrooke's Hospital, Cambridge CB2 2QQ

Kay-Tee Khaw, professor in clinical gerontology

Mary-Jane Sneyd, research fellow, clinical gerontology unit

Juliet Compston, Wellcome senior lecturer and honorary consultant, department of medicine

Correspondence to: Professor Khaw, Clinical Gerontology Unit.

BM于 1992;305:273-7 bone formation or an increase in bone resorption. Parathyroid hormone and vitamin $\mathrm{D}$ are clearly critical in calcium homoeostasis, but their role in determining bone density is not clear. Serum parathyroid hormone concentrations rise with age whereas 25-hydroxycholecalciferol and 1,25-dihydroxycholecalciferol concentrations decline. Though differences in parathyroid hormone concentrations have been noted in association with gross osteoporosis, results from recent studies disagree on whether changes in these values are a result of or causally related to bone density or bone mineral content. ${ }^{46}$ Vitamin D deficiency is a well recognised cause of osteomalacia, and subclinical vitamin D deficiency - though insufficient to cause osteomalacia - may lead to secondary hyperparathyroidism and bone loss. Though it has also been implicated in senile osteoporosis, ${ }^{78}$ its role remains debatable. A recent review on prevention of osteoporosis and fractures made no mention of vitamin D. ${ }^{9}$ We examined the relation between bone density and 25 -hydroxyvitamin $D$ and parathyroid hormone concentrations in middle aged white British women who had no known osteoporosis.

\section{Subjects and methods}

The data reported were collected as part of a pilot validation study of different dietary measurement methods conducted in 1989-90. Women from the general community were recruited by mailing all women aged 45-65 from two general practice registers in Cambridge requesting volunteers who were prepared to undertake dietary assessments over one year. The purpose of this study was to compare different methods of dietary assessment including weighed measured intake and food records. Women were asked to continue their usual dietary intake patterns throughout this study. After detailed explanations roughly $20 \%$ of the women volunteered. They were unselected for health status. The dietary data are currently being coded and analysed.

During this study women had bone density measured by dual energy $x$ ray absorptiometry with the LUNAR DPX densitometer. ${ }^{10}$ Bone density measurements were conducted during March, April, and May. At the bone density visit height and weight were also measured with the women in light clothing and without shoes. Body mass index was calculated as weight in kilograms divided by square of the height in metres. Bone mineral density was estimated from bone mineral content divided by area measured at specific sites (areal density). For these analyses we used the bone mineral density measured from three sites: lumbar spine (L2, L3, L4) and neck and trochanteric regions of the left femur. The precision values for lumbar spine and neck and trochanteric regions were $1 \cdot 2 \%, 2 \cdot 5 \%$, and $2 \cdot 2 \%$ respectively.

A non-fasting blood sample was obtained for bio- 
chemical studies at the time of the bone density appointment, between 930 am and $4 \mathrm{pm}$. All blood samples were centrifuged within two hours of venepuncture and frozen at $-70^{\circ} \mathrm{C}$. They were retrieved six months later for the biochemical assays. Serum alkaline phosphatase, phosphate, and calcium values were measured in a routine biochemistry laboratory. Serum intact parathyroid hormone (1-84) concentrations were estimated by a two site immunoradiometric assay ${ }^{11}$ (intra-assay coefficient of variation $3.5 \%$ ) and concentrations of 25-hydroxycholecalciferol (vitamin $\mathrm{D}_{2}$ ) and 25-hydroxyergocalciferol (vitamin $\mathrm{D}_{3}$ ) measured by the method of Preece $e t a l^{12}$ (intra-assay coefficient of variation $2 \cdot 7 \%$ ).

Statistical analyses were undertaken on the University of Cambridge computer by using the statistical package for the social sciences (SPSSX). Crude correlation coefficients of bone density and biochemical variables with age and body mass index were calculated. The relations between bone mineral density and indices of calcium metabolism were then examined before and after adjusting for age by using regression techniques. Partial correlation coefficients, which are the correlations between bone mineral density and biochemical indices when the linear effects of body mass index and age have been removed, were also calculated. Analysis of variance techniques were used to examine mean bone densities at different sites by tertile of biochemical variable after adjusting for the linear effects of age and body mass index.

\section{Results}

A total of 139 women in the dietary study had bone density and biochemical measurements. We excluded the one woman who reported a history of hip fracture, leaving 138 women for analysis. Table I shows the distribution of variables in these women. Table II shows the correlations of bone density, bone mineral content, and biochemical values with age and with body mass index after adjusting for age. Serum parathyroid hormone concentration was not related to age or body mass index. Serum 25-hydroxyvitamin D concentration was not related to age but was negatively

TABLE I-Distribution of variables in 138 women

\begin{tabular}{lcc}
\hline & Mean $(\mathrm{SD})$ & Range \\
\hline Age (years) & $56 \cdot 6(4 \cdot 7)$ & $45-65$ \\
Body mass index $\left(\mathrm{kg} / \mathrm{m}^{2}\right)$ & $25 \cdot 0(4 \cdot 1)$ & $18 \cdot 0-45 \cdot 6$ \\
Serum biochemistry: & $2 \cdot 06(1 \cdot 10)$ & $0 \cdot 1-8 \cdot 4$ \\
$\quad$ Parathyroid hormone $(\mathrm{pmol} / \mathrm{l})$ & $28 \cdot 85(11 \cdot 56)$ & $3.97-58 \cdot 16$ \\
25-Hydroxyvitamin D $(\mathrm{nmol} / \mathrm{l})$ & $98(28)$ & $46-192$ \\
Alkaline phosphatase $(\mathrm{IU} / \mathrm{l})$ & $2 \cdot 17(0 \cdot 08)$ & $1 \cdot 98-2 \cdot 58$ \\
Calcium $(\mathrm{mmol} / \mathrm{l})$ & $1 \cdot 14(0 \cdot 14)$ & $0 \cdot 84-1 \cdot 58$ \\
Phosphate $(\mathrm{mmol} / \mathrm{l})$ & & \\
Bone mineral density $\left(\mathrm{g} / \mathrm{cm}^{2}\right):$ & $1 \cdot 11(0 \cdot 17)$ & $0 \cdot 77-1 \cdot 64$ \\
$\quad$ Lumbar & $0 \cdot 88(0 \cdot 12)$ & $0 \cdot 58-1 \cdot 22$ \\
Neck & $0 \cdot 77(0 \cdot 11)$ & $0 \cdot 49-1 \cdot 07$ \\
Trochanter & & \\
\hline
\end{tabular}

TABLE II-Correlation coefficients of biochemical and bone measure ment variables with age and body mass index (age adjusted) in 138 women aged 45-65

\begin{tabular}{lcc}
\hline & \multicolumn{2}{c}{ Correlation coefficient $(r)$ of variable with: } \\
\cline { 2 - 3 } & Age & $\begin{array}{c}\text { Body mass index } \\
\text { (age adjusted) }\end{array}$ \\
\hline Body mass index $\left(\mathrm{kg} / \mathrm{m}^{2}\right)$ & $0 \cdot 14$ & \\
Serum biochemistry: & $0 \cdot 05$ & $0 \cdot 01$ \\
Parathyroid hormone & $0 \cdot 16^{\star}$ & $-0 \cdot 25^{\star \star}$ \\
25-Hydroxyvitamin D & $0 \cdot 21^{\star \star}$ & $0 \cdot 18^{\star}$ \\
Alkaline phosphatase & $0 \cdot 09$ & $0 \cdot 04$ \\
Calcium & $0 \cdot 18^{\star}$ & $-0 \cdot 14$ \\
Phosphate & $-0 \cdot 23^{\star \star}$ & $0 \cdot 22^{\star \star}$ \\
Bone mineral density: & $-0 \cdot 07$ & $0 \cdot 28^{\star \star \star}$ \\
Lumbar & $0 \cdot 01$ & $0 \cdot 37^{\star \star \star}$ \\
Neck & & \\
Trochanter & & \\
\hline
\end{tabular}

${ }^{\star} \mathrm{p}<0.05 .{ }^{\star \star} \mathrm{p}<0.01 .{ }^{\star \star \star} \mathrm{p}<0.001$. related to body mass index. Serum alkaline phosphatase and serum phosphate values but not serum calcium concentrations were positively correlated with age. Within this $45-65$ year age range lumbar bone mineral density was negatively correlated with age but femoral neck and trochanteric bone mineral densities were not. All measures of bone density correlated strongly with body mass index. The association was strongest for the trochanter.

Table III shows mean age adjusted and body mass index adjusted bone density levels by tertile of biochemical variable using analysis of variance. Table III also shows age adjusted and body mass index adjusted partial correlation coefficients of bone density with biochemical variables. Bone density at all three sites was significantly negatively correlated with serum parathyroid hormone concentrations and positively correlated with serum 25-hydroxyvitamin D concentrations. Bone density was also negatively correlated with serum calcium concentrations and positively correlated with serum phosphate concentrations. Though correlations were significant only for the lumbar spine, the relations were in consistent directions for all sites. Analyses were repeated after excluding separately the few current cigarette smokers $(n=9)$, premenopausal women $(n=26)$, women currently using postmenopausal hormone replacement therapy $(n=19)$, and women reporting using thiazide diuretics $(n=7)$. Findings were similar.

Table IV shows the mean age and body mass index adjusted serum concentrations of parathyroid hormone, 25-hydroxyvitamin D, alkaline phosphatase, calcium, and phosphate by quartile of bone density at lumbar spine, femoral neck, and trochanter. At each site the lowest bone density quartile was associated with higher serum parathyroid hormone and calcium concentrations and lower serum 25 -hydroxyvitamin D and phosphate concentrations compared with the highest bone density quartile.

\section{Discussion}

The associations between bone density at the three sites and parathyroid hormone and 25-hydroxyvitamin D concentrations were significant, though not large. That such associations were apparent at all was surprising given the large measurement errors inherent in this study. Only one non-fasting blood sample was used to characterise the parathyroid hormone and vitamin D status of the individual. The intraindividual measurement variability of both these variables is considerable. Diurnal as well as episodic fluctuation in parathyroid hormone secretion is well recognised, with $N$ maximal secretion in midmorning, resulting in large intraindividual variation. ${ }^{13}$ Though individual maximal diurnal variation may be around $40 \%$, blood for biochemical studies was taken during the working day, when intraindividual variation is much lower. However, random measurement error and ensuing reduction in power is likely to reduce any associations, not produce a spurious one. Similarly, the significant negative relation of bone density with serum calcium concentration, even within the narrow and tightly controlled normal range of serum calcium values, was also surprising.

The findings for phosphate concentrations, though not always significant, were in consistent directions. Bone density did not relate to total alkaline phosphatase activity. Unfortunately, we did not have specific measures for bone alkaline phosphatase activity. These associations were also independent of menopausal ? status and other potentially confounding factors such as body mass index and cigarette smoking habit.

Though these women were not a random population sample but volunteers who were prepared to undertake 
TABLE III-Age and body mass index adjusted (by analysis of variance) mean bone mineral densities at different sites by tertile of serum parathyroid hormone, 25-hydroxyvitamin $D$, alkaline phosphatase, calcium, and phosphate values, and age and body mass index adjusted partial correlation coefficients of bone density and bone mineral content at various sites with biochemical variables in 138 women aged 45-65

\begin{tabular}{|c|c|c|c|c|}
\hline & \multicolumn{3}{|c|}{$\begin{array}{l}\text { Age and body mass index adjusted mean tertile of } \\
\text { biochemical variable }\end{array}$} & \multirow{2}{*}{$\begin{array}{l}\text { Partial correlation } \\
\text { coefficient }(r) \\
\text { (age and body mass } \\
\text { index adjusted) }\end{array}$} \\
\hline & 1 & 2 & 3 & \\
\hline \multicolumn{5}{|c|}{ Lumbar bone mineral density: } \\
\hline Parathyroid hormone & $1 \cdot 15$ & $1 \cdot 10$ & 1.08 & $-0 \cdot 18^{\star}$ \\
\hline 25-Hydroxyvitamin D & $1 \cdot 12$ & 1.09 & $1 \cdot 15$ & $0 \cdot 18^{\star}$ \\
\hline Alkaline phosphatase & $1 \cdot 11$ & $1 \cdot 14$ & 1.08 & -0.08 \\
\hline Calcium & $1 \cdot 14$ & $1 \cdot 12$ & 1.07 & $-0 \cdot 19^{\star}$ \\
\hline Phosphate & 1.08 & $1 \cdot 10$ & $1 \cdot 12$ & $0 \cdot 17^{\star}$ \\
\hline \multicolumn{5}{|l|}{ Neck bone mineral density: } \\
\hline Parathyroid hormone & 0.91 & 0.88 & 0.84 & $-0 \cdot 21^{\star \star}$ \\
\hline 25-Hydroxyvitamin D & 0.87 & 0.87 & 0.90 & $0 \cdot 22^{\star \star}$ \\
\hline Alkaline phosphatase & 0.88 & 0.87 & 0.89 & -0.08 \\
\hline Calcium & 0.89 & 0.89 & 0.85 & $-0 \cdot 11$ \\
\hline Phosphate & 0.87 & $0 \cdot 88$ & 0.90 & 0.08 \\
\hline \multicolumn{5}{|c|}{ Trochanteric bone mineral density: } \\
\hline Parathyroid hormone & $0 \cdot 78$ & 0.79 & 0.75 & $-0 \cdot 15^{\star}$ \\
\hline 25 -Hydroxyvitamin D & 0.76 & $0 \cdot 77$ & 0.79 & $0.19^{\star}$ \\
\hline Alkaline phosphatase & $0 \cdot 78$ & 0.77 & 0.76 & $-0 \cdot 11$ \\
\hline Calcium & 0.79 & 0.78 & 0.74 & $-0 \cdot 16^{\star}$ \\
\hline Phosphate & 0.77 & 0.77 & 0.79 & 0.77 \\
\hline
\end{tabular}

${ }^{\star} \mathrm{p}<0.05 .{ }^{\star \star} \mathrm{p}<0.01$

TABLE IV-Age and body mass index adjusted (by analysis of variance) mean biochemical values by quartiles of bone mineral density at various sites in 138 women aged 45-65

\begin{tabular}{|c|c|c|c|c|}
\hline & \multicolumn{4}{|c|}{$\begin{array}{l}\text { Age and body mass index adjusted mean quartile of } \\
\text { bone mineral density at site indicated }\end{array}$} \\
\hline & 1 & 2 & 3 & 4 \\
\hline \multicolumn{5}{|l|}{ Lumbar bone mineral density: } \\
\hline Parathyroid hormone (pmol/1) & $2 \cdot 27$ & $2 \cdot 25$ & 1.90 & $1 \cdot 82^{\star}$ \\
\hline 25-Hydroxyvitamin D (nmol/1) & $25 \cdot 23$ & $30 \cdot 02$ & $29 \cdot 38$ & $30 \cdot 75^{\star}$ \\
\hline Alkaline phosphatase (IU/l) & 98 & 108 & 92 & 95 \\
\hline Calcium $(\mathrm{mmol} / \mathrm{l})$ & $2 \cdot 21$ & $2 \cdot 16$ & $2 \cdot 16$ & $2 \cdot 16^{\star}$ \\
\hline Phosphate $(\mathrm{mmol} / \mathrm{l})$ & $1 \cdot 12$ & $1 \cdot 13$ & $1 \cdot 10$ & $1 \cdot 20^{\star}$ \\
\hline \multicolumn{5}{|l|}{ Neck bone mineral density: } \\
\hline Parathyroid hormone (pmol/l) & $2 \cdot 27$ & $2 \cdot 10$ & $2 \cdot 08$ & $1 \cdot 80^{\star \star}$ \\
\hline 25-Hydroxyvitamin D (nmol/l) & $27 \cdot 43$ & $27 \cdot 08$ & $29 \cdot 68$ & $31 \cdot 32^{\star \star}$ \\
\hline Alkaline phosphatase (IU/l) & 98 & 103 & 104 & 88 \\
\hline Calcium $(\mathrm{mmol} / \mathrm{l})$ & $2 \cdot 19$ & $2 \cdot 18$ & $2 \cdot 18$ & $2 \cdot 14$ \\
\hline Phosphate $(\mathrm{mmol} / \mathrm{l})$ & $1 \cdot 13$ & $1 \cdot 12$ & $1 \cdot 14$ & $1 \cdot 17$ \\
\hline \multicolumn{5}{|l|}{ Trochanteric bone mineral density: } \\
\hline Parathyroid hormone $(\mathrm{pmol} / \mathrm{l})$ & $2 \cdot 36$ & 2.09 & 1.95 & $1 \cdot 85^{\star}$ \\
\hline 25-Hydroxyvitamin $\mathrm{D}(\mathrm{nmol} / \mathrm{l})$ & $28 \cdot 70$ & $26 \cdot 51$ & $27 \cdot 38$ & $33 \cdot 72^{\star}$ \\
\hline Alkaline phosphatase (IU/l) & 102 & 102 & 99 & 90 \\
\hline Calcium $(\mathrm{mmol} / \mathrm{l})$ & $2 \cdot 19$ & $2 \cdot 18$ & $2 \cdot 16$ & $2 \cdot 16^{\star}$ \\
\hline Phosphate (mmol/l) & $1 \cdot 12$ & $1 \cdot 13$ & $1 \cdot 11$ & $1 \cdot 16$ \\
\hline
\end{tabular}

Significance values for age and body mass index adjusted partial correlations: ${ }^{\star} \mathrm{p}<0.05,{ }^{\star \star} \mathrm{p}<0.01$.

detailed dietary studies, they were recruited from the general community and not selected with regard to any disease - in particular, not osteoporosis. Hence it is unlikely that selection bias would account for our findings. There is no reason to believe that the internal relation between bone density and biochemical variables in this cohort would differ qualitatively from that in the general population. In terms of the distribution of characteristics such as body mass index and biochemical variables the subjects resembled other British study populations where data are available. ${ }^{14}$ The consistency of findings with different measures of bone density and the stepwise dose-response relation with hormone and associated biochemical variables, even in this heterogeneous group and despite the likely measurement errors, together with the concomitant biochemical relations suggest that the association is real.

Though the magnitude of the associations of bone density with parathyroid hormone, vitamin $\mathrm{D}$, and related serum biochemical values was not large, they may still have considerable implications.

\section{PROPOSED MODELS OF BONE LOSS}

The relation between bone density and parathyroid hormone was apparent over the whole normal distribution of both bone density and parathyroid hormone values and hence is likely to indicate a physiological relation. It is not clear whether the higher parathyroid hormone concentrations are a consequence of or may cause lower bone density levels. Two models of bone loss have been proposed. The type I model suggests that low oestrogen concentrations result in low calcitonin concentrations, increased bone resorption, increased plasma calcium values, reduction in parathyroid hormone and 1,25-dihydroxycholecalciferol concentrations, and decreased intestinal calcium absorption. ${ }^{15}$ The type II model postulates the primary problem as low intestinal absorption of calcium possibly because of low concentrations of 1,25 dihydroxycholecalciferol or by virtue of low calcium intake. ${ }^{16}$ Reduction in plasma calcium concentration results in increased parathyroid hormone (secondary hyperparathyroidism) and 1,25-dihydroxycholecalciferol concentrations and ensuing increased bon resorption. There is still controversy over which mechanism is predominant. The type I model predicts low parathyroid hormone and high serum calcium concentrations; the type II model predicts high parathyroid hormone and low serum calcium concentrations. The type I model is thought to predominate in osteoporosis in postmenopausal women whereas the type II model is thought to predominate in osteoporosis in elderly people.

Based on their findings of lower parathyroid hormone concentrations in postmenopausal women than in premenopausal women, Stevenson and Whitehead suggested that the type I model was more dominant in perimenopausal and postmenopausa women. ${ }^{15}$ Our findings of high parathyroid hormone and serum calcium concentrations and lower phosphate concentrations in association with lower bone densities suggest that, in common with the type II model, reduced bone density is a consequence, not a cause, of changes in parathyroid hormone concentrations. However, the higher serum calcium concentrations are not consistent with the hypothesis that parathyroid hormone is increased secondary to a low serum calcium concentration but, rather, indicate a third possibility-namely, that some exogenous stimulus other than low serum calcium concentration might be responsible for a primary increase in parathyroid hormone concentration which then results in increased bone resorption and concomitant higher serum calcium and lower phosphate concentrations. If this is the case, then research needs to be directed towards what determines a rise in parathyroid hormone concentrations in normal subjects which is not responsive to the increased serum calcium.

Several studies have indicated that parathyroid hormone concentrations can be considerably influenced by exogenous environmental factors. Calvo et al reported persistently increased parathyroid hormone secretion and action in women after high phosphorus, low calcium diets. ${ }^{17}$ Parathyroid hormone concentrations were highest in elderly subjects with low vitamin D status. Hypertrophy of the parathyroid glands is well known complication of vitamin D deficiency. However, parathyroid hormone concentrations seem to be influenced by vitamin $\mathrm{D}$ status even at levels no generally considered clinically deficient. The majo source of vitamin D is skin manufacture in the presence of sunlight. ${ }^{19}$ In sunlight deprived elderly people there is an inverse relation between parathyroid hormone and 25-hydroxyvitamin D concentrations. Seasonal variation in parathyroid hormone concen trations (highest in winter) has been recorded both in postmenopausal women ${ }^{21}$ and in elderly people ${ }^{22}$ and is inversely related to 25 -hydroxyvitamin $\mathrm{D}$ concentrations (lowest in winter). The seasonal variation in elderly people was abolished by vitamin $D_{3}$ supplementation of $400 \mathrm{IU}$ daily.

\section{HYPOTHESIS}

Our results suggest that 25 -hydroxyvitamin $\mathrm{D}$ has a role in determining bone density, even in peri- 
menopausal and postmenopausal women, not just in elderly people, and are compatible with the hypothesis that the effects of low 25-hydroxyvitamin D concentrations on bone may be mediated through parathyroid hormone. This hypothesis is consistent with several observations. Villareal et al reported that postmenopausal women with low vertebral bone mass had lower circulating 25-hydroxyvitamin D concentrations and generally increased parathyroid hormone concentrations compared with controls. ${ }^{23}$ Some case-control studies have also shown that subjects with hip fracture have significantly lower serum 25-hydroxyvitamin $\mathrm{D}$ concentrations than controls. ${ }^{24-26}$ There is a pronounced seasonal variation in bone density (lowest in winter ${ }^{27}$ as well as hip fracture incidence (highest in winter) ${ }^{28}$ coincidental with the winter seasonal decrease in serum 25 -hydroxyvitamin $\mathrm{D}$ concentrations. Hip fracture incidence is also greatest with increasing latitude. ${ }^{29}$ There has been a doubling of hip fracture incidence in both sexes in Britain in the past 30 years. ${ }^{30}$ During this time dietary vitamin $\mathrm{D}$ has declined, mainly owing to the halving of fish consumption..$^{31}$

The vitamin D hypothesis could also explain some of the observed relations between physical activity or calcium intake and osteoporosis and fractures as well as some of the inconsistencies in the data. In the United States milk-the main source of calcium-is also vitamin $\mathrm{D}$ fortified. The strong inverse relation between dietary calcium and subsequent hip fracture in the Rancho Bernardo prospective study in California $^{32}$ could possibly also be due to vitamin $\mathrm{D}$, which closely correlates with milk intake. Where milk is not vitamin D fortified, as in Britain, such associations may not be found. ${ }^{33}$ It is also notable that studies which have found an association between physical activity and bone density or fractures generally defined physical activity as outdoor activities..$^{33} 34$ Sunlight could be a confounding factor. Additionally, active people have higher serum 25-hydroxyvitamin D concentrations than inactive people. ${ }^{35}$

Trials of the effects of vitamin D supplementation on osteoporosis have had mixed results. ${ }^{36-39}$ However, most of these have used 1,25-dihydroxyvitamin D analogues such as alfacalcidol. Unfortunately, we did not have the resources to measure 1,25-dihydroxycholecalciferol concentrations. Though 1,25-dihydroxycholecalciferol is recognised as the most biologically active, 25-hydroxyvitamin $\mathrm{D}$ is several magnitudes more abundant in the body, and the two forms may well affect bone differently.

\section{PUBLIC HEALTH IMPLICATIONS}

The public health implications may be considerable. The relation of bone density to 25 -hydroxyvitamin D and parathyroid hormone values was apparent through the whole range, not just at 25-hydroxyvitamin D concentrations considered clinically deficient, though it is notable that this cohort of women had generally low mean concentrations overall compared with an American cohort. ${ }^{21}$ Prospective studies indicate that fracture risk increases in a stepwise manner with decreasing bone density through the whole range of bone density. Most fractures in a population occur not in the small numbers of women at the extreme bottom end of the distribution, who are at highest risk, but in the large numbers of women in the centre of the normal distribution, who are at moderately increased risk. A shift to the right of the population distribution of bone density by as little as $5 \%$ in mean bone density may result in a $20 \%$ decrease in fractures-more than could be achieved by a screening programme treating those in the lowest $10 \%$ for bone density. This is analogous to the population strategy for preventing cardiovascular disease by shifting favourably the population distri- bution of risk factors such as blood pressure and serum cholesterol values. ${ }^{40}$

From this cohort we can estimate that an increase in serum vitamin $\mathrm{D}$ concentrations of $40 \mathrm{nmol} / \mathrm{l}$ would be associated with a $5-10 \%$ increase in bone density. This could be achievable by sunlight exposure of face and lower arms and legs for 30 minutes a day (not an amount likely to increase skin cancer risk appreciably) or increasing daily adult vitamin D intake from the current mean of $100 \mathrm{IU}$ to $400 \mathrm{IU}$, a dose several magnitudes below levels which are potentially toxic (reported toxic effects in adults occur with doses of around 100000 IU daily for a prolonged period). If such a change in average vitamin $D$ status in the population, from 20 to $60 \mathrm{nmol} / 1$, well within the normal range, can influence parathyroid hormone concentrations, bone density, and subsequent fracture risk, this may indicate areas for possible preventive intervention.

This work was supported by grants from the Wellcome Trust, the Violet $M$ Richards Charity, the Wolfson Trust, and the East Anglia Regional Health Authority.

1 Wasnich RD, Ross PD, Heilbrun LK, Vogel JM. Prediction of postmenopausal fracture risk with use of bone mineral measurements. Am J Obstet Gynecol 1985;153:745-51.

2 Hui SL, Slemenda W, Johnston CC Jr. Age and bone mass as predictors of fracture in a prospective study. $\mathcal{F}$ Clin Invest 1988;81:1804-9.

3 Cummings SR, Black DM, Nevitt MC, Browner WS, Cauley JA, Genant HK, et al. Appendicular bone density and age predict hip fracture in women. FAMA 1990;263:665-8.

4 Tsai K-S, Ebeling PR, Riggs BL. Bone responsiveness to parathyroid hormone in normal and osteoporotic postmenopausal women. fClin Endocrinol Metab 1989;69:1024-7.

5 Silverberg SJ, Shane E, De La Cruz L, Segre GV, Clemens TL, Bilezikian JP. Abnormalities in parathyroid hormone secretion and 1,25 . dihydroxyvitamin D3 formation in women with osteoporosis. N Englf $\mathrm{Med}$ 1989:320:277-81.

6 Raisz LG. Local and systemic factors in the pathogenesis of osteoporosis. NEnglf Med 1988;318:818-28.

7 Tsai K-S, Heath III H, Kumar R, Riggs BL. Impaired vitamin D metabolism with ageing in women. $\mathcal{F}$ Clin Invest 1984;73:1668-72.

8 Parfitt AM, Gallagher JC, Heaney RP, Johnston CC, Neer R, Whedon GD Vitamin $D$ and bone health in the elderly. Am $\mathcal{F}$ Clin Nutr 1982;36:1014-31. Law MR, Wald NJ, Meade TW. Strategies for prevention of osteoporosis and hip fractures. BMf 1991;303:453-9.

10 Mazess RB, Barden HS. Bone densitometry for diagnosis and monitoring osteoporosis. Proc Soc Exp Biol Med 1989;191:261-71.

11 Lindall AW, Elting J, Ells J, Roos BA. Estimation of biologically active parathyroid hormone in normal and hyperparathyroid sera by sequential $\mathrm{N}$-terminal immunoextraction and midregion radioimmunoassay. fClin Endocrinol Metab 1983;57:1007.

12 Preece MA O'Riordan JLH, Lawson DEM, Kodicek E. A competitive protein binding assay for 25-hydroxycholecalciferol and 25-hydroxyerocalciferol in serum. Clin Chim Acto 1974;54:235-42.

13 Calvo MS, Eastell R, Offord KP, Bergstralh EJ, Burritt MF. Circadian variation in ionized calcium and intact parathyroid hormone: evidence fo sex differences in calcium homeostasis. F Clin Endocrinol Metab 1991;72: 69-76.

14 Gregory J, Foster K, Tyler H, Wiseman M, Office of Population Censuses and Surveys. The dietary and nutritional survey of British adults. London: HMSO, 1990.

15 Stevenson JC, Whitehead M. Postmenopausal osteoporosis. BMF 1982;285: 585-8.

16 Riggs B, Melton L. Evidence for two distinct syndromes of involutional osteoporosis. Am J Med 1983;75:889-901.

17 Calvo MS, Kumar R, Heath III H. Persistently elevated parathyroid hormone $\frac{D}{O}$ secretion and action in young women after 4 weeks of ingesting high phosphorus, low calcium diets. $\mathcal{F}$ Clin Endocrinol Metab 1990;70:1334-40.

18 Frame B, Parfitt AM. Osteomalacia: current concepts. Ann Intern Med 1978;89:966-82.

19 Holick MF. The photobiology of vitamin $D$ and its consequences for humans. Ann N Y Acad Sci 1985;453:1-14.

20 Gloth III FM, Tobin JD, Sherman SS, Hollis BW. Is the recommended daily allowance for vitamin D too low for the homebound elderly? 7 Am Geriatr Soc allowance for vitamin $\mathrm{D}$ too low for the homebound elderly? $\mathcal{F}$ Am Geriatr Soc

21 Krall EA, Sahyoun N, Tannenbaum S, Dallal GE, Dawson-Hughes B. Effect $\stackrel{\mathscr{\infty}}{?}$ of vitamin D intake on seasonal variations in parathyroid hormone secretion in postmenopausal women. $N$ Engl $\mathcal{F}$ Med 1989;321:1777-83.

22 Lips $\mathrm{P}$, Wiersinga A, van Ginkel FC, Jongen MJM, Netelenbos JC, Hackeng WHL, et al. The effect of vitamin D supplementation on vitamin D status and parathyroid function in elderly subjects. $\mathcal{J}$ Clin Endocrinol Metab 1988;67:644-9.

23 Villareal DT, Civitelli R, Chines A, Avioli LV. Subclinical vitamin D deficiency in postmenopausal women with low vertebral bone mass. J Clin Endocrinol Metab 1991;72:628-34.

24 Lund B, Sorensen OH, Christensen AB. 25-Hydroxycholecalciferol and $\frac{O}{0}$ fractures of the proximal femur. Lancet 1975;ii:300-2.

25 Baker MR, McDonnell H, Peacock M, Nordin BEC. Plasma 25-hydroxyvitamin $D$ concentrations in patients with fractures of the femoral neck. BMF 1979;i:589.

26 Lips P, Van Ginkel FC, Jongen MJM, Rubertus F, van der Viigh WJF Netelenbos JC. Determinants of vitamin $D$ status in patients with hip fracture and in elderly control subjects. Am f Clin Nutr 1987;46:1005-10.

27 Aiken JM, Anderson JB. Seasonal variations in bone mineral content after the menopause. Nature 1973;241:59-60 
28 Jacobsen SJ, Goldberg J, Miles TP, Brody JA, Stiers W, Rimm AA. Seasona ariation in the incidence of hip fracture among white persons aged 65 years and older in the United States. Am F Epidemiol 1991;133:996-1004.

29 Cummings SR, Kelsey JL, Nevitt MC, O'Dowd KJ. Epidemiology of osteoporosis and osteoporotic fractures. Epidemiol Rev 1985;7:178-207.

30 Boyce WJ, Vessey MP. Rising incidence of fracture of the proximal femur Lancet 1985; ;:150-1.

31 Committee on Medical Aspects of Food Policy. The fortification of yellow fats with vitamins $A$ and $D$. London: HMSO, 1991. (Department of Health Report on Health and Social Subjects, No 40 .

32 Holbrook TL, Barrett-Connor E, Wingard DL. Dietary calcium and risk of hip fracture: 14-year prospective population study. Lancet 1988;ii:1046-9.

33 Wickham CAC, Walsh K, Cooper C, Barker DJP, Margetts BM, Morris J, et al. Dietary calcium, physical activity, and risk of hip fracture: et al. Dietary calcium, physical activity,

34 Lau E Donnan S, Barker DJP, Cooper C. Physical activity and calcium intake in fracture of the proximal femur in Hong Kong. $B M F$ 1988;297:1441-6.
35 Scragg R, Holdaway I, Jackson R, Lim T. Plasma 25-hydroxyvitamin D3 and its relation to physical activity and other heart disease risk factors in the its relation to physical activity and other heart disease

36 Ott SM, Chesnut CH. Calcitriol treatment is not effectve in postmenopausal Ott SM, Chesnut CH. Calcitriol treatment is no

37 Gallagher JC, Riggs BL, Recker RR, Goldgar D. The effect of calcitriol on patients with postmenopausal osteoporosis with special reference to fracture frequency. Proc Soc Exp Biol Med 1989;191:287-92.

38 Aloia JF, Vaswani A, Yeh JK, Ellis K, Yasumura S, Cohn SH. Calcitriol in the treatment of postmenopausal osteoporosis. Am J Med 1988;84:401-8.

39 Parfitt AM. Use of calciferol and its metabolites and analogs in osteoporosis; current status. Drugs 1988;36:513-20.

40 Rose G. Strategy of prevention: Lessons from cardiovascular disease. $B M \mathcal{T}$ $1981 ; 282: 1847-51$

(Accepted 1 fune 1992)

\title{
Low serum cholesterol concentration and short term mortality from injuries in men and women
}

\author{
Gunnar Lindberg, Lennart Råstam, Bo Gullberg, Gunnar A Eklund
}

\section{Abstract}

Objective-To determine whether total serum cholesterol concentration predicts mortality from injuries including suicide.

Design-Cohort study of men and women who had their serum cholesterol concentration measured as part of a general health survey in Värmland, Sweden in 1964 or 1965 and were followed up for an average of 20.5 years.

Subjects-Adults participating in health screening in 1964-5 (26693 men and 27692 women). The study sample was restricted to subjects aged 45-74 years during any of the 20.5 years of follow up.

Main outcome measures-Serum cholesterol concentration. Deaths from all injuries and suicides during three periods of follow up (0-6 years, 7-13 years, and 14-21 years) according to the Swedish mortality register in subjects aged 45-74. Adjustment was made for prevalent cancer (identified from the Swedish cancer register) at the time of a suicide.

Results-A strong negative relation between cholesterol concentration and mortality from injuries was found in men during the first seven years of follow up. The relative risk in the lowest $25 \%$ of the cholesterol distribution was 2.8 (95\% confidence interval 1.52 to 4.96 ) compared with the top $25 \%$. Most of the excess risk was caused by suicide with a corresponding relative risk of $4 \cdot 2$ ( $p$ for trend $=0 \cdot 001$ ). Correction for prevalent cancer did not change the results. Events occurring during the latter two thirds of the 20.5 years of follow up were not predicted. In women no relation between cholesterol concentration and mortality from injuries was found.

Conclusions-Together with observations from intervention trials the findings support the existence of a relation between serum cholesterol concentration and suicide. The causality of such a relation is, however, not resolved.

\section{Introduction}

"A moratorium on the use of cholesterol lowering drugs," has recently been suggested based partly on the observation in clinical trials that the intervention groups suffer an excess mortality from injuries. ${ }^{23} \mathrm{~A}$ meta-analysis including six such primary prevention trials showed an increased mortality in men from "causes not related to illness." This excess risk was found in drug trials as well as in diet trials. ${ }^{4}$ Prospective observational studies covering the relation between serum cholesterol concentration and deaths from injuries are, however, inconclusive. ${ }^{56}$
Observational studies might be biased by confounding. There is a relation between low serum cholesterol concentration and the incidence of cancer. Suicides constitute an important fraction of all deaths from injuries. Hypothetically, if seriously ill subjects suffer a higher risk of suicide, coexistent cancer might confound a negative correlation between serum cholesterol concentration and suicide. Other hypotheses about possible links between mortality from injuries and cholesterol concentration have been reviewed by Muldoon ${ }^{4}$ and Pekkanen.

One reason for the inconsistent findings in previous cohort studies may be that the numbers of events were too small. In this study data from a large cohort of men and women followed up for two decades were used to investigate the association between total serum cholesterol concentration and mortality from injuries. A special attempt was made to investigate the impact of cancer incidence on such a relation.

\section{Subjects and methods}

The study sample from the subcohort of the Värmland survey that was included in this study has been previously described. ${ }^{8}$ In summary, data on several chemical analyses, including serum cholesterol concentration, were collected from 26693 men and 27692 women who participated in a general health survey conducted in Värmland, Sweden, in 1964-5. The participation rate was $78 \cdot 1 \%$ in men aged $25-74$ years and $81.3 \%$ in women of the same age. Serum total cholesterol was analysed on one occasion in non-fasting subjects. A modified Liebermann-Burchard method described by Zak et al was used. ${ }^{9}$

The Swedish mortality register, which is regarded as reliable,$^{10}$ was used to identify fatal events in the cohort from 1964 to 1985 . In the register the underlying cause of death is coded according to the International Classification of Diseases. The seventh revision ${ }^{11}$ was used for deaths occurring from 1964-8 and the eighth revision $^{12}$ for deaths occurring from 1969 onwards. In both editions injuries are defined by the codes E 800 to E 999 (see table I). In the seventh edition suicide is defined by the codes E 970 to E 979 and in the eighth edition by the codes E 950 to E 959 . Only deaths occurring between the ages of 45 and 74 in subjects who were 25-74 years old at the health examination were considered. Consequently, the study sample was restricted to those who were aged 45-74 years during any of the 20.5 years of follow up. This design has been used in previous studies of this cohort. ${ }^{8}$

The Swedish cancer register was used to identify 